Review Article

\title{
Production Constraints and Improvement Strategies of Cowpea (Vigna unguiculata L. Walp.) Genotypes for Drought Tolerance
}

\author{
Gabriel V. Nkomo ${ }^{1},{ }^{1,2}$ Moosa M. Sedibe, ${ }^{1}$ and Maletsema A. Mofokeng ${ }^{2}$ \\ ${ }^{1}$ Department of Agriculture, Central University of Technology Free State, Bloemfontein, South Africa \\ ${ }^{2}$ Agriculture Research Council Grain Crops, Potchefstroom, South Africa \\ Correspondence should be addressed to Gabriel V. Nkomo; gvnkomo@gmail.com
}

Received 11 January 2021; Revised 12 February 2021; Accepted 10 March 2021; Published 22 March 2021

Academic Editor: Cristina Patan ; cristinamaria.patane@cnr.it

Copyright @ 2021 Gabriel V. Nkomo et al. This is an open access article distributed under the Creative Commons Attribution License, which permits unrestricted use, distribution, and reproduction in any medium, provided the original work is properly cited.

\begin{abstract}
Cowpea (Vigna unguiculata L. Walp. L) is an important leguminous crop largely grown by smallholder farmers in sub-Saharan Africa for food security and animal feed. The objective of this study was to review the production constraints and improvement strategies of cowpea genotypes for drought tolerance. Data were analysed through use of literature review from various sources. In sub-Saharan Africa, cowpeas are produced mainly from West Africa, which accounts for $60 \%$ of worldwide production. A lot of pests and diseases affect cowpeas, and this often results in total crop loss. Through continuous improvement, many new cultivars are continually being identified and genetically characterised, and it is thus necessary to evaluate these new lines under different environments. There is a need for multidisciplinary collaborations among breeders and other relevant stakeholders such as farmer and extension workers because the improved cultivars must be according to the farmers preferred traits. Due to declining rainfall pattern in sub-Saharan Africa, there is an urgent requirement for cowpea breeding programmes that focus on developing varieties with short maturity, drought, pest, and disease tolerance. The present review discusses the constraints and improvement strategies of cowpea varieties for drought tolerance.
\end{abstract}

\section{Introduction}

Cowpea originated in Africa though the exact place of domestication is not well known. Ethiopia, Central Africa, Central and Southern Africa, and West Africa are considered as possible centers of origin $[1,2]$. Apart from nutrients, cowpea has dietary fibre, antioxidants and polyunsaturated fatty acids (PUFA), and polyphenols [2]. Thus, cowpea is a very important crop in Africa. Information on the production constraints and farmer's views, perceptions, and variety preferences in Zimbabwe are not yet fully documented. However, Mujaju and Mazvimavi [3] assessed seed security in the four most vulnerable districts in Zimbabwe. These four districts were Mudzi, Binga, Buhera, and Mwenezi, which are always prone to droughts. The results showed that farmers need good quality drought-tolerant cultivars and that there is a need for extension training on selection, grading, and postharvest management of good quality local and recycled seed.

\section{Cowpea Production Worldwide}

According to FAOSTAT (2017), cowpea was grown on an estimated 11 million ha in Africa in 2017 with most of production confined to West Africa (10.6 million ha), especially in Niger, Nigeria, Burkina Faso, Mali, and Senegal. More than 7.4 million tons of cowpeas are produced worldwide, with Africa producing nearly 5.2 million tons (https://www.iita.org/cropsnew/cowpea/). According to FAOSTAT (2017), over $87 \%$ of cowpeas are produced in Africa. However, in South America, Brazil increased cowpea cultivation and the country is now in third place in terms of global production.

Nigeria is the largest producer and consumer of cowpeas and accounts for $61 \%$ of the production in Africa and $58 \%$ worldwide [4]. Fifty-two percent of Africa's production of cowpeas is used for food, $13 \%$ as animal feed, $10 \%$ for seeds, $9 \%$ for other uses, and $16 \%$ is wasted [4]. 


\section{Importance of Cowpea}

Cowpea is mainly consumed as dry grain or fresh vegetable.. The grain contains high protein, carbohydrate, vitamins, and fibre [5]. In addition, it has low fat content, which is important in the prevention of diverse metabolic and cardiovascular diseases [6]. The amino acid and vitamin profiles of the grain supplement those of cereals. According to Hall [5], in the smallholder farming areas where it is mainly grown, cowpea is the cheapest source of protein. Cowpea has many beneficial uses as animal feed, human consumption, and income generation (IITA, 2009). In some cases, the pods are harvested when they are fullsized, just before they dry out, and then the grains are cooked and eaten as avegetable. The consumption of cowpea as a fresh vegetable has rapidly increased in the semi-arid zone of Africa especially Senegal $[5,7]$. The earlymaturing cowpea varieties are important as they provide food during the ravenous time of August and September, before other crops such as pearl millet, sorghum, and other landraces of cowpeas and peanuts are harvested in October [5]. According to Hall [5], depending on the region, fresh pods of cowpea cultivars have various names: in Kenya (African green beans), Trinidad (beans), and Southeast Asia (yard-long beans). The roughage is utilized as food for animals during the long dry season in the semi-arid areas and to fatten small ruminants in anticipation of different celebrations [5]. Cowpeas are important also as they improve the fertility of the soil in terms of nitrogen and phosphate. Studies show that some cowpea cultivars prevent the emergence of the seeds of Striga hermonthica, which parasitizes pearl millet, sorghum, and maize [8]. Also, Lee and Thierfelder [9] noted that intercropping with cowpea has been known to suppress and smother weeds in dryland farming systems in the smallholder farming sector. Other cowpea varieties have been observed to suppress the populations of the nematode Scutellonema cavenessi, which is a major pest of pearl millet, sorghum, and peanut in the Sahel [5]. In some cropping systems, cowpeas can be used as cover crops and these can suppress pests, many plant pathogens including nematodes, and increase carbon sequestration [10].

\section{Constraints of Cowpea Production}

Several biotic and abiotic factors such as insect pests, diseases (fungal, viral and bacterial), poor soil fertility, metal toxicity, and drought contribute to the reduction of cowpea yield potential in sub-Saharan Africa [11-13]. Other factors contributing to low yield in sub-Saharan Africa include lack of improved varieties that can withstand these stresses and lack of adequate production practices and inputs needed for higher productivity and profitability. This yield gap therefore can be bridged if improved varieties and production practices are available to farmers through participatory on-farm training and evaluation with farmers [14]. Among the abiotic factors, drought has been identified as a major limitation restricting cowpea production in Southern Africa [12].

\section{Effect of Drought on Cowpea Production}

Drought has been reported as a major constraint in semiarid tropics due to erratic rainfall in the beginning and towards the end of the rainy season [15]. The crop is usually subjected to drought stress in both seedling and terminal growth stages, and this causes substantial reduction in grain yield as well as biomass production. Drought conditions can either be intermittent when they occur at one or more intervals during the crops' growing period or terminal when there is progressive decrease in available soil moisture content resulting in severe drought [16]. Iwuagwu et al. [17] reported that the effects of drought vary and depend on the intensity, developmental stage, and duration of stress as well as the adaptive strategy that the plant possesses to tolerate this stress. During the vegetative phase, water deficit causes leaf and plant growth reduction, alteration in the process of nutrient absorption due to low water availability in the environment, increase in stomatal resistance, and ultimately, a decrease in gaseous exchange between the environment and the plant $[12,18]$. Water stress leads to a decrease in plant water content and turgor reduction and results in a decrease in cellular expansion [17]. Thus, there is a need for the establishment of effective breeding programs that can develop high-yielding and well-adapted varieties for water deficit conditions. Olajide et al. [15] noted that drought is one of the most important abiotic constraints threatening food security in the world. This is because the livelihoods of African farmers depend on rain-fed agricultural systems that are seriously affected during periods of severe drought; thus, drought is a serious phenomenon in Africa [19].

\section{Strategies Used to Mitigate Drought}

Various adaptive measures are used by farmers to mitigate the effects of drought. From a survey conducted in the smallholder farming sector, Umdale et al. [20] observed that most farmers preferred to change their cropping calendar to adjusted planting or to use drought-tolerant crops to mitigate the impact of drought. Some farmers opt to cultivate early maturing varieties as these are considered climatesmart cultivars that can withstand terminal dry spell as well as pests and diseases damage that regularly occur later in the farming season [21]. The early-maturing cowpea cultivars in the range of 55 and 60 days are ideal in agroecological zones with short growing seasons. This is because they provide food sooner than any other harvest, hence shortening the hunger period [21]. According to Oxfam [22], farmers in Zimbabwe have resorted to utilising various techniques to mitigate drought. In marginal districts of the country, farmers are resorting to drought-tolerant alternatives such as indigenous crops like sorghum, pearl millet, cowpeas, and groundnuts. Farmers firmly believe that these crops are suited to dry conditions. Farmers are additionally planting a combination of crops and varieties to minimize risk. This limits crop failure as some varieties are likely to yield significantly even under low moisture conditions. Finally, in some instances, during dry spell years, farmers might be compelled to replant multiple times [22]. However, this 
coping strategy has the disadvantage of farmers failing to access sufficient seed on time as well as subjecting the crops to less moisture.

\section{Vegetative-Stage Drought Resistance}

Research has shown that cowpeas possess considerable resistance to vegetative-stage drought in California [23]. When cowpea seeds were planted in a soil profile with enough water to allow germination and emergence, they survived for 43 days under very hot dry summer conditions with no rain, but were badly stunted. This endurance of vegetative-stage drought was due to increased leaf water retention in cowpea than pearl millet [24]. Cowpeas exhibit little changes in leaf water and osmotic potential when exposed to drought [25]. Cowpeas also have stomata that are very sensitive to soil drying, partially closing before any changes in leaf water potential are detected [25]. When cowpea plants are subjected to drought in field conditions, their leaves do not dry out but are arranged vertically following the sun in a way that limits the exposure of solar radiation [26]. These mechanisms add to the capacity of cowpeas to withstand extraordinary vegetative-stage drought that kills most alternative crop plants. A screening method to test for the endurance of drought at the seedling stage was developed that uses a shallow soil layer in boxes [27]. When 190 cowpea-breeding lines from the International Institute of Tropical Agriculture (IITA) were screened with this technique, only $22 \%$ were found to be susceptible to drought. This showed that most current cowpea lines might have resistance to vegetative-stage drought. Inheritance studies indicated that susceptibility was due to a single recessive gene [27]. Studies show that cowpeas endure seedling-stage drought longer than any other single crop species tried including lablab beans, bambara groundnuts, peanuts, pearl millet, sorghum, green gram, dark gram, maize, and soybeans [5]. Hall [5] however reported that there are two conditions where the resistance of cowpeas to vegetativestage drought is not viable. The first condition is when the cowpea plants are contaminated with a soil-borne disease called ashy stem blight disease (Macrophomina phaseolina). This is because the resistance of cowpeas to vegetative-stage drought breaks down and the plants die. This disease organism is widespread and causes severe damage to cowpea developing in the hot, dry soil conditions that frequently happen in the semi-arid zone and Botswana. The second condition is when the cowpea plants have been attacked by the lesser cornstalk borer (Elasmopalpus lignosellus). Infested plants were killed during drought while plants in well-watered treatments survived.

\section{Coping with Mid-Season Drought}

There are various studies that have been carried out with respect to resistance to mid-season drought [5, 28-30]. An example, line 58-57, was chosen from a landrace growing around the Senegal River that flower at 41 days after sowing and reaches maturity in 75 days [31]. Goufo et al. [6] investigated osmo-adaptation in leaves and roots using photosynthetic traits, water homeostasis, inorganic ions, and primary and secondary metabolites. The results showed the assignment of high amounts of amino acids, sugars, and proanthocyanidins into roots that were assumed to be linked to growth and initial stress adaptation. Out of the 88 metabolites studied, proline, galactinol, and quercetin derivative responded most to drought. These metabolites accumulated in roots, which suggests a more conservative strategy to cope with drought in the aerial parts [6].

\section{Use of Multiple Cowpea Cultivars}

In regions where rainfall is variable and irregular dry spells, a single type of cowpea cultivar is not ideal, as it does not meet the needs of farmers. It is consequently critical to raise multiple kinds of cultivars with the goal that farmers grow at least two types every year to enhance the chances of significant grain and hay production [32]. Early-maturing varieties that have been developed such as Ein El Gazal, which matures in 60 days from planting, can escape from late-season dry spell and furthermore have protection from vegetative-stage dry spell [33]. However, even though the early erect cultivars provide useful food during the hunger period, they are prone to midseason drought and produce little hay. Spreading cultivars like 58-57 with a mediumcycle of 75 days also have significant protection from midseason and vegetative-stage drought [32]. The disadvantage with these varieties is that they produce grain and hay only when the season is short. Ibitoye [16] observed that crosses TVu6707 x TVU9797, TVu9693 x TVu7778, and TVu9693 x TVu9797 had more grain yield and seeds per pod and were drought tolerant. A comparison was made between varietal intercrops consisting of alternating rows of extraearly erect cultivars and medium-cycle spreading cultivars with sole crops of the same cultivars within the semi-arid zone of Senegal [34]. The varietal intercrops made extra grain and roughage under dry conditions with infertile soil and were more stable than any of the sole crops of cowpeas that were tested. In screening for drought tolerance at the seedling stage for 23 cowpea varieties, Muhammad et al. [35] observed that five varieties, Kanannado, Danila, IT07K-29713, IT03K-378-4, and Aloka local, were highly tolerant to drought. In an analysis to distinguish morpho-physiological parameters for selecting drought-tolerant cowpea varieties, it was found out that Danila was the most tolerant variety [36]. When there is a mid-season drought, the early maturing cultivar becomes stunted while the medium-cycle spreading cultivar grows and yields more when intercropped. When the rainy season is short, it has been observed that the early maturing cultivars produce a lot of grain, while the medium-cycle spreading cultivars produce a lot of hay but with little grain in the intercrop [34]. Nadeem et al., [37] observed that root length, fibrous root system, density, and rooting depth are promising factors that are useful for screening genotypes for drought stress tolerance. Duc et al. [38] highlighted that early flowering; pod formation and maturity are mechanisms that are very useful in mass screening. An early erect cultivar that matures in 60-65 days, Vuli-1, was developed for short rains in Tanzania [39]. 
However, the major disadvantages of these extra-early erect cowpea cultivars are that they must be planted at close spacing, they produce next to no roughage and they can be wiped out by a late-season drought [34].

\section{Genetic Diversity in Cowpeas Based on Molecular Markers}

Genetic diversity refers to the differences of heritable qualities present in a population of one species, and it is an important aspect that serves as a way for populations to adapt to changing environments [40]. When there is more variation, some individuals in a population will have variations of alleles that are adapted to a particular condition. Wamalwa et al. [41] evaluated genetic diversity from 19 accessions of cowpeas from the national genebank of Kenya. The accessions clustered into two major groups, namely, Ethiopian and Australian. These cowpea accessions showed high levels of divergence to the accessions from Western Kenya. From this evaluation, diversity is important as it can be used to improve other existing cowpeas accession through further selection and breeding. According to Nadeem et al. [42] molecular markers are nucleotide sequences that are investigated through the polymorphism present between the nucleotide sequences of different individuals. Molecular markers are classified into various groups based on (1) mode of gene action (co-dominant or dominant markers), (2) method of detection (hybridizationbased molecular markers or polymerase chain reaction(PCR-)) based markers, and (3) mode of transmission (paternal organelle inheritance, maternal organelle inheritance, biparental nuclear inheritance, or maternal nuclear inheritance). These markers are widely used because of their high prevalence and expression in different stages of the organisms [43]. Batieno et al. [44] noted that markers based on single nucleotide polymorphisms (SNPs) are increasingly being used in molecular genetics in recent years. This is due to their abundance in the genomes and their amenability for high-throughput detection and automation in many genotyping platforms [45]. Among these platforms is the LGC genomics', United Kingdom, that provides DNA sequence data to scientists using Kompetitive Allele-Specific PCR (KASP). SNP markers are progressively being employed for a large number of genetic as well as diversity studies. Such studies are reported in pea [46], cowpea [29, 47], and cassava [48]. SNPs provide a large number of markers to be used in diversity studies or marker-assisted breeding. SNPs are codominant markers, and they are most often linked to genes. Thus, they are the foremost enticing genetic markers in genetic studies [49]. The use of SNPs might also facilitate clustering of germplasm that help breeders to have enlightened alternatives of parents for breeding functions. SNP markers, therefore, facilitate decision making once the variability within the germplasm is identified. Alghamdi et al. [50] used sequence-related amplified polymorphisms (SRAPs) markers to assess genetic variability in seven cowpea landraces using seed storage proteins. Igwe et al. [51] used intersimple sequence repeat (ISSR) and start codontargeted (SCoT) polymorphic markers to assess the genetic diversity in eighteen Vigna unguiculata L. (Walp) accessions. Mafakheri et al. [52] characterised 32 cowpea genotypes for molecular markers using a set of 22 Simple Sequence Repeat (SSR) primer pairs. In their study, 186 alleles were detected with an average of 2 alleles for each locus, and genetic distance between genotypes was estimated at 0.0066. Xiong et al. [53] observed that the level of genetic diversity tends to have a positive correlation with the geographic origin from which the accessions were collected. In their study of genetic diversity and population structure of 768 cowpea types from 56 countries, Xiong et al. [53] found that there was high genetic diversity of accessions from South and West Africa, which had seven and eight countries, respectively. Similarly, the lowest genetic diversity of accessions was from Europe with only two countries. In analyzing genetic diversity of 370 landraces, Fatokun et al. [54] observed that cluster one had 115 accessions from the largest number of countries and thus the highest genetic diversity, heterozygosity, and polymorphic information content. Recently, one of the other platforms being used for genetic studies is Diversity Arrays Technology, Australia (DArTseq ${ }^{\mathrm{TM}}$ ), that produces SNPs at relatively lower costs. DArTseq ${ }^{\mathrm{TM}}$ provides a good choice as a high-throughput marker genotyping platform that can develop a relatively large number of polymorphic markers to build dense genetic maps with low-cost investments (http:// www.diversityarrays.com/). The use of high-density genetic maps based on DArTseq ${ }^{\mathrm{TM}}$ technology increases the power of quantitative trait loci (QTL) detection. Also, DArTseq ${ }^{\mathrm{TM}}$ technology is ideal for polypoid species as well as the rapid development of any genome. As a result, DArTseq ${ }^{\mathrm{TM}}$-derived markers are currently used in more than 400 species (http:// www.diversityarrays.com/), mainly for crops with nonsequenced genomes. Several researchers have used DArTseq ${ }^{\mathrm{TM}}$ technology to investigate genetic diversity across different crop species. Killian et al. [55] applied DArTseq ${ }^{\mathrm{TM}}$ technology to pineapple to understand the genetic relationships between the genotypes. SNP markers were used in the characterization of 113 cowpea accessions from Ghana and abroad [47]. The results revealed 477 SNPs, out of which 458 were polymorphic. Fatokun et al. [54] used genotyping by sequencing on 298 lines from the loosely composed mini core collection of 370 landraces in cowpeas to assess genetic diversity and population structure. The study revealed three different clusters.

\section{Molecular Breeding in Cowpeas for Drought Tolerance}

Agbicodo et al. [28] noted that two important different methods could be used to identify genes that are tolerant to drought in cowpea. One of the methodologies would be to identify candidate genes related to drought tolerance from previous research in cowpea and other related crops. Another and regularly utilized methodology is to recognize differential expression of mRNAs in drought stressed compared with control plants. Shimelis and Horn [56] also used another approach of optimal cycle lengths determination to identify genes that are tolerant to drought in cowpea. In cowpea studies, several successful attempts have been made to construct genetic maps throughout the use of 
SNPs and other markers. Muchero et al. [57] constructed a genetic map of seven populations of cowpea recombinant inbred lines (RILs) based on SNPs. Consensus genetic linkage maps give a genomic framework for quantitative attribute loci identification, map-based cloning, assessment of genetic diversity, and association mapping and applied breeding in marker-assisted selection schemes. Consensus genetic linkage maps give a genomic framework for quantitative attribute loci identification, map-based cloning, assessment of genetic diversity, association mapping, and applied breeding in marker-assisted selection schemes. In crops such as cowpea $(2 \mathrm{n}=2 x=22)$ with limited genomic data, the use of transcript-derived SNPs in genetic maps provides opportunities for automated genotyping and estimation of genome structure based on chromosome analysis. Muchero et al. [58] further reports that SNP mining from 183,118 ESTs sequenced from $17 \mathrm{cDNA}$ libraries yielded 10,000 high-confidence SNPs from which an Illumina 1,536-SNP Golden Gate genotyping array was developed and applied to 741 recombinant inbred lines from six mapping populations. Approximately $90 \%$ of the SNPs were technically successful, providing 1,375 dependable markers. Of these, 928 were incorporated into a consensus genetic map spanning $680 \mathrm{cM}$ with 11 linkage groups and a median marker distance of $0.73 \mathrm{cM}$. Pan et al., [59] identified 34,868 SNPs that were distributed in the cowpea genome based on the (restriction-site associated DNA sequencing) technique using a population of 170 accessions developed from two cowpea bi-parental crosses. Of these, 17,996 reliable SNPs were assigned to 11 consensus linkage groups (LGs). The length of the genetic map was $1,194.25 \mathrm{cM}$ in total with a mean distance of $0.066 \mathrm{cM} / \mathrm{SNP}$ marker locus. Using this map and the F2:3 population, combined with the CIM (composite interval mapping) method, eleven quantitative trait loci (QTL) of the yield-related trait were detected on seven LGs (LG4, 5, 6, 7, 9, 10, and 11) in cowpea. Such characterization of molecular markers can greatly aid breeders in marker-assisted cowpea breeding and improvement.

\section{Association Mapping in Cowpeas for Drought Tolerance}

For effective selection in cowpea, it is imperative to have knowledge of genetic variability and estimate character association and heritability of important agronomic traits. These estimates are important and help in the design of selection strategies for cowpea breeding programs. Muchero et al. [58] used Kruskall-Wallis and multipleQTL model mapping to assess the QTL that is associated with drought response phenotypes. Ravembola et al. [60] used genomewide association studies (GWAS) to identify SNPs that were associated with various tolerance index traits including drought. The results indicated that the number of significant SNPs differed among the tolerance index traits. The highest number of SNP markers was for grain yield, indicating that a large number of loci contributed to high yield in cowpea genotypes subjected to low moisture levels. Kouam et al. [61] studied character associations, phenotypic and genotypic divergence for yield and yield-related quantitative traits among 30 cowpea landraces in Cameroon. The results indicated that broad sense heritability was high with 20 traits out of 25 having heritability values greater than $70 \%$. The highest heritability was for 100 seed weight $(98.15 \%)$ and the lowest for shoot weight (41.38\%). At a 0.05 probability level, grain yield correlated significantly with 21 out of the 24 other quantitative traits. In cowpea, besides drought, salinity has also become an increasing threat to production, and Ravelombola et al. [62] identified SNPs associated with salt tolerance at germination and seedling stages. A total of 1049 SNPs postulated from genotyping-by-sequencing were used for association analysis. Three SNPs were highly associated with salt tolerance at the germination stage, while seven SNPs were found to be associated with salt tolerance at seedling stage. These markers can be applied as a tool for selecting salt-tolerant lines to be included in breeding programs of this crop.

\section{Farmer-Extension Participation in Breeding and Adoption of New Technologies}

Smallholder farmers both in Zimbabwe and in South Africa face many challenges in the production of legumes such as cowpea; one of them is their low yield. It has been suggested that farmers' participation in the early stages of any breeding program can contribute to the acceptance and adoption of new improved cultivars [63] as their needs and expectations will likely be met. Other participatory studies conducted in cowpea revealed that farmers' participation in varietal selection could improve the effectiveness and efficiency of the selection process given that farmers' selection intensity was similar to that of the breeders [64]. Interaction and collaboration between farmers and researchers is important as it takes into consideration farmers' perceptions on the major constraints affecting crop production as well as their preferences on the crop traits and cultivars. Ngaka and Zwane [65] concur that surveys in agriculture are important in assisting decision-makers in future planning to strengthen extension and advisory services. Extension services are one of the policy instruments that can be used to solve the food insecurity challenges.

The active involvement of farmers is important in the understanding of underlying decision-making factors for farmers to adopt or not-to-adopt agricultural innovations. Maruzani [66] carried out a survey to assess problems faced by rural women in the Buhera District of Manicaland South Province of Zimbabwe. The study showed that poverty resulting from the depletion of natural resources and gender inequality were the underlying causes of the problems that rural women face. Mubaiwa et al. [67] surveyed seven districts in semi-arid regions of rural Zimbabwe to gather knowledge on current production and utilization of Bambara groundnut, to assess its role in providing sustainable food and nutrition security for rural populations, and to determine priorities. The survey was carried out in Uzumba, Binga, Buhera, Mudzi, Pfungwe, Lower Gweru, and Bikita. Farmers in these districts use various processing techniques among them boiling, soaking, roasting, and milling. 
Masegela and Oluwatayo [68] evaluated value chain mapping and marketing efficiency of smallholder cowpea farmers in Capricorn and Waterberg districts of Limpopo province in South Africa. The study revealed that $66 \%$ of the smallholder cowpea farmers were market efficient and $34 \%$ were market inefficient. It was also revealed that women were more involved in cowpea production than men were. Maseko et al. [69] assessed production and utilization in South Africa of African leafy vegetables. The assessment revealed that there is a lack of suitable production systems, innovative processing, and value-adding techniques that promote the utilization of African leafy vegetables. It was also observed that African leafy vegetables are food for the poor among the youth and urban folks, while, among the affluent, they are highly regarded as being nutritious.

Technologies that do not meet farmers' preferences, objectives, and conditions are less likely to be adopted [70]. Farmers are more likely to assess a technology with criteria and objectives that are different from criteria used by scientists. However, farmers' and scientists' criteria for technology assessment are complementary and essential for effective research and technology development. Acceptance of the technology as a new farming method in the community will have an impact on its continued promotion and existence in the community. In this context, participation is crucial. Participatory research is crucial as it allows the incorporation of farmers' indigenous technical knowledge, identification of farmers' criteria and choices, and definition of research agenda. There is a need to train farmers on new technology and innovations to improve their appreciation of the methods, more so in areas where farmers have limited opportunities [71].

Extension information is very vital and needs to be carefully disseminated in a way that is well understood by even those with little formal education. Thompson et al. [72] evaluated producers' perspectives of four key precision agriculture technologies (variable-rate fertilizer application, precision soil sampling, guidance, and auto-steer, and yield monitoring) in terms of the benefits they provide to their farms. The results indicated that farmers' perceptions of the benefits derived from various precision agriculture technologies were diverse. Most farmers reported the benefits to be yield improvement or cost reduction. The reason for differing perceptions was that farmers need information and benefits that accrue from the adoption of a technology to use. Maredia et al. [73] evaluated farmer perception in seed quality in bean and seed auctions in Tanzania and Ghana. The study concluded that there was a need to increase the availability of qualitatively better-performing seed that is affordable to smallholder farmers. It was also observed that there is a need to lower the cost of producing higher quality certified seed so that more farmers have access to the seed as this helps to have a more vibrant seed system. So, by integrating farmers' concerns and conditions into agricultural research, the developed technologies may be widely adopted, resulting in more productive, stable, equitable, and sustainable agriculture. Further, understanding farmers' preferences is important for the successful adoption of improved varieties.

\section{Conclusion}

Cowpea is a drought-tolerant legume crop widely grown for food, fodder, and vegetable by smallholder farmers in subSaharan Africa and other warm-hot regions of the world with limited rainfall. Its productivity is mainly affected by biotic and abiotic stresses. Even though it is an important crop, there has been very limited progress achieved in breeding against these stress factors through conventional breeding. Research and development of improved cowpea cultivars must lead to increased production in diverse agroecological environments. The use of next-generation sequencing techniques (NGS) has, however, greatly revolutionized plant breeding. These technologies allow for the sequencing of cowpea DNA more quickly and cheaply thus saving costs for breeders. There is a need for multidisciplinary collaborations among breeders and other relevant stakeholders such as farmers and extension workers. This is because the improved cultivars must be according to the farmer's preferred traits. Due to the declining rainfall pattern in sub Saharan Africa, there is an urgent requirement for different cowpea breeding programs that focus on developing varieties with short maturity, drought, pest, and disease tolerance.

\section{Conflicts of Interest}

The authors declare that they have no conflicts of interest.

\section{Acknowledgments}

The review was supported by the Central University of Technology, Free State Research Grant Scheme, and Agriculture Research Council Grain Crops, Potchefstroom.

\section{References}

[1] NQ. Ng and R. Marechal, "Cowpea taxonomy, origin and germplasm," in Cowpea Research, Production and Utilization, S. R. Singh and K. O. Rachie, Eds., pp. 11-21, John Wiley \& Sons, Chichester, NY, USA, 1985.

[2] AC. Da Silva, D. C. Santos, and D. L. T. Junior, Cowpea: A Strategic Legume Species for Food Security and Health, IntechOpen, London, UK, 2018.

[3] Mujaju C., Mazvimavi K. 2019. Seed Security Assessment of the 4 Most Vulnerable Districts in Zimbabwe. http:// Agroecologyconference.co.za/wp-content-uploads/2019/02/ Claid-Mujaju-Seed-security-assessment-Zimbabwe.pdf.

[4] N. S. Baysah, Assessing the Effect of Seed Quality Characteristics on the Growth and Yield of Four Cowpea (Vigna Unguiculata Walp) Varieties, MSc Thesis, Kwame Nkrumah University of Science and Technology, Kumasi, Ghana, 2013.

[5] A. E. Hall, "Phenotyping cowpea for adaptation to drought," Frontiers in Physiology, vol. 25, 2012.

[6] A. Gonçalves, P. Goufo, A. Barros et al., "Cowpea (Vigna unguiculata L. Walp), a renewed multipurpose crop for a more sustainable agri-food system: nutritional advantages and constraints," Journal of the Science of Food and Agriculture, vol. 96, no. 9, pp. 2941-2951.

[7] TrindadeDomínguez-Perles M. D. 2017. Sahel Region, Africa. http://theconversation.com/sahel-region-africa-72569. 
[8] H. Samejima and Y. Sugimoto, "Recent research progress in combatting root parasitic weeds," Biotechnology \& Biotechnological Equipment, vol. 32, no. 2, pp. 221-240, 2018.

[9] N. Lee and C. Thierfelder, "Weed control under conservation agriculture in dryland smallholder farming systems of southern Africa. A review," Agronomy for Sustainable Development, vol. 37, p. 48, 2017.

[10] KH. Wang and R. McSorley, Management of Nematodes with Cowpea Cover Crops, EDIS, Gainesville, FL, USA, 2018, http:// edis.ifas.ufl.edu.

[11] JO. Saka, OA. Agbeleye, OT. Ayoola, BO. Lawal, JA. Adetumbi, and Q. O. Oloyede-Kamiyo, "Assessment of varietal diversity and production systems of cowpea (Vigna unguiculata (L.) walp.) in southwest Nigeria," Journal of Agriculture and Rural Development in the Tropics and Subtropics, vol. 119, no. 2, pp. 43-52, 2018.

[12] O. Boukar, N. Belko, S. Chamarthi et al., "Cowpea (Vigna unguiculata): genetics, genomics and breeding," Plant Breeding, vol. 138, no. 4, pp. 415-424, 2018.

[13] A. MF. Gomes, N. Nhantumbo, M. Ferreira-Pinto et al., Breeding Elite Cowpea [Vigna unguiculata (L.) walp] Varieties for Improved Food Security and Income in Africa: Opportunities and Challenges, IntechOpen, London, UK, 2019.

[14] H. A. Ajeigbe, BB. Singh, JO. Adeosun, and I. E. Ezeaku, "Participatory on-farm evaluation of improved legume-cereals cropping systems for crop-livestock farmers. Maizedouble cowpea in northern Guinea savannah zone of Nigeria," African Journal of Agriculture Research, vol. 5, pp. 2080-2088, 2010.

[15] A. A. Olajide and C. O. Ilori, "Genetic variability, performance and yield potentials of ten varieties of cowpea (Vigna unguiculata (L) walp) under drought stress," Legume Genomics and Genetics, vol. 8, pp. 17-25, 2017.

[16] D. Ibitoye, "Performance of cowpea [Vigna unguiculata (L.) walp] hybrids under drought induced and well-watered conditions," TEEAL Research Paper Competition, pp. 1-19, 2015.

[17] MO. Iwuagwu, CI. Ogbonnaya, and N. B. Onyike, "Physiological response of cowpea [Vigna unguiculata (L.) walp.] to drought: the osmotic adjustment resistance strategy," Academic Journal of Science, vol. 07, no. 02, pp. 329-344, 2017.

[18] T. O. Abidoye, Effects of Soil Moisture Content on Growth and Yield of Cowpea (Vigna Unguiculata (L) Walp), Msc Agriculture Dissertation, University of Ilorin, Ilorin, Nigeria, 2004.

[19] E. Oladipo, "Climate change and sustainable livelihoods: greening options for Nigeria," Report of the First National Environmental Summit on the Theme: Greening the Environment for Sustainable Development, pp. 83-95, 2008.

[20] P. Umdale, Y. Ichikawa, S. Manandhar, H. Ishidaira, and A. S. Kiem, "Farmers' perception of drought impacts, local adaptation and administrative mitigation measures in Maharashtra state, India," International Journal of Disaster Risk Reduction, vol. 10, pp. 250-269, 2014.

[21] EY. Owusu, R. Akromah, NN. Denwar, J. Adjebeng-Danquah, F. Kusi, and M. Haruna, "Inheritance of early maturity in some cowpea (Vigna unguiculata (L.) walp.) genotypes under rain fed conditions in northern Ghana," Advances in Agriculture, vol. 2018, Article ID 8930259, 10 pages, 2018.

[22] Oxfam 2016. Our Seeds: Lessons Learnt from the Drought. Voices of Farmers in Zimbabwe. https://www-cdn.oxfam.org/ s3fs-public/bn-our-seeds-food-security-zimbabwe-151216en.pdf.
[23] K. J. Turk, A. E. Hall, and C. W. Asbell, "Drought adaptation of cowpea. I. Influence of drought on seed yield 1," Agronomy Journal, vol. 72, no. 3, pp. 413-420, 1980.

[24] C. Petrie and A. Hall, "water relations in cowpea and pearl millet under soil water deficits. I. Contrasting leaf water relations," Functional Plant Biology, vol. 19, no. 6, pp. 577-589, 1992.

[25] K. Shackel and A. Hall, "Comparison of water relations and osmotic adjustment in sorghum and cowpea under field conditions," Functional Plant Biology, vol. 10, no. 5, pp. 423-435, 1983.

[26] KA. Shackel and A. E. Hall, "Reversible leaflet movements in relation to drought adaptation of cowpeas, Vigna unguiculata (L) walp," Australian Journal of Plant Physiology, vol. 6, pp. 265-276, 1979.

[27] BB. Singh and T. Matsui, "Cowpea varieties for drought tolerance," in Challenges and Opportunities for Enhancing Sustainable Cowpea Production, C. A. Fatokun, S. A. Tarawali, B. B. Singh, P. M. Kormawa, and M. Tamò, Eds., IITA, Ibadan, Nigeria, 2002.

[28] E. M. Agbicodo, C. A. Fatokun, S. Muranaka, R. G. F. Visser, and C. G. Linden van der, "Breeding drought tolerant cowpea: constraints, accomplishments, and future prospects," Euphytica, vol. 167, no. 3, pp. 353-370, 2009.

[29] BL. Huynh, TJ. Clos, PA. Roberts et al., "Gene pools and the genetic architecture of domesticated cowpea," Plant Genome, vol. 6, p. 8, 2013.

[30] S. E. Mwale, M. Ochwo-Ssemakula, K. Sadik et al., "Response of cowpea genotypes to drought stress in Uganda," American Journal of Plant Sciences, vol. 08, no. 04, pp. 720-733, 2017.

[31] C. D. Li, C. A. Fatokun, B. Ubi, B. B. Singh, and G. J. Scoles, "Determining genetic similarities and relationships among cowpea breeding lines and cultivars by microsatellite markers," Crop Science, vol. 41, no. 1, pp. 189-197, 2001.

[32] A. E. Hall, "Breeding for adaptation to drought and heat in cowpea," European Journal of Agronomy, vol. 21, no. 4, pp. 447-454, 2004.

[33] H. O. A. Elwad and A. E. Hall, "Registration of Ein El Gazal cowpea," Crop Science, vol. 42, pp. 1745-1746, 2002.

[34] S. Thiaw, A. E. Hall, and D. R. Parker, "Varietal intercropping and the yields and stability of cowpea production in semiarid Senegal," Field Crops Research, vol. 33, no. 3, pp. 217-233, 1993.

[35] I. Muhammad, MA. Ramlatu, and B. G. Zakari, "Screening of selected varieties of cowpea seedlings [Vigna unguiculata (L.) walp.] for drought tolerance," Journal of Biology and Nature, vol. 5, pp. 31-38, 2015.

[36] FD. Pele, A. Yeboah, MS. Buari, and E. J. Kofi, "Morphophysiological parameters used in selecting drought tolerant cowpea varieties using drought index," African Journal of Agriculture, vol. 3, pp. 125-134, 2016.

[37] M. Nadeem, J. Li, M. Yahya et al., "Research progress and perspective on drought stress in legumes: a review," International Journal of Molecular Sciences, vol. 20, no. 10, p. 2541, 2019.

[38] G. Duc, H. Agrama, S. Bao et al., "Breeding annual grain legumes for sustainable agriculture: new methods to approach complex traits and target new cultivar ideotypes," Critical Reviews in Plant Sciences, vol. 34, no. 1-3, pp. 381-411, 2015.

[39] J. K. Mligo and B. B. Singh, "Registration of 'vuli-1' cowpea," Crop Science, vol. 47, no. 1, p. 437, 2007.

[40] P. Xu, Y. Jiang, J. Xu, J. Li, and X. Sun, "Genomics in the common carp," Genomics in Aquaculture, vol. 2016, pp. 247-274, 2016. 
[41] E. NI. Wamalwa, J. Muoma, and C. Wekesa, "Genetic diversity of cowpea (Vigna unguiculata (L.) walp.) accession in Kenya gene bank based on simple sequence repeat markers," International Journal of Genomics, vol. 2016, Article ID 8956412, 2016.

[42] M. A. Nadeem, M. A. Nawaz, M. Q. Shahid et al., "DNA molecular markers in plant breeding: current status and recent advancements in genomic selection and genome editing," Biotechnology \& Biotechnological Equipment, vol. 32, no. 2, pp. 261-285, 2018.

[43] Kodrostami M., Rashim M. 2015. Molecular Markers in Plants: Concepts and Applications. Review Article. https://researchgate. net/publication/282954774_Molecular_Markers_in_Plants_: Concepts_and_Applications.

[44] T. BJ. Batieno, O. Souleymane, JB. Tignegre et al., "Single nucleotide polymorphism (SNP)-Based genetic diversity in a set of Burkina Faso cowpea germplasm," African Journal of Agriculture Research, vol. 13, pp. 978-987, 2018.

[45] J. Mammadov, R. Aggarwal, R. Buyyarapu, and S. Kumpatla, "SNP markers and their impact on plant breeding," International Journal of Plant Genomics, vol. 2012, Article ID 728398, 11 pages, 2012.

[46] C. Deulvot, H. Charrel, A. Marty et al., "Highly-multiplexed SNP genotyping for genetic mapping and germplasm diversity studies in pea," BMC Genomics, vol. 11, no. 1, pp. 468-477, 2010.

[47] K. F. Egbadzor, K. Ofori, M. Yeboah et al., "Diversity in 113 cowpea [Vigna unguiculata (L.) walp] accessions assessed with 458 SNP markers," Springer, vol. 3, p. 541, 2014, http:// www.fao.org/faostat/en/\#data/QC.

[48] R. Thompson, Genetic Analysis of Postharvest Physiological Deterioration in Cassava (Manihot Esculenta Crantz) Storage Roots, PhD Thesis, University of Ghana, Ghana, West Africa, 2013.

[49] G. L. Jiang, "Molecular markers and marker-assisted breeding in plants," in Plant Breeding from Laboratories to Field, S. B. Anderson, Ed., pp. 45-83, Croatia: In Technology, Croatia, 2013.

[50] SS. Alghamdi, MA. Khan, HM. Migdadi, EH. El-Hart, M. Afzal, and M. Farooq, "Biochemical and molecular characterization of cowpea landraces using seed storage proteins and SRAP marker patterns," Saudi Journal of Biological Sciences, vol. 26, 2018.

[51] DO. Igwe, CA. Afiukwa, BE. Ubi, KI. Ogbu, OB. Ojuederi, and G. N. Ude, "Assessment of genetic diversity in Vigna unguiculata $\mathrm{L}$. (Walp) accessions using inter-simple sequence repeat (ISSR) and start codon targeted (Scot) polymorphic markers," BMC Genetics, vol. 18, Article ID 98, 2017.

[52] K. Mafakheri, MR. Bihamta, and A. R. Abbasi, "Assessment of genetic diversity in cowpea (Vigna unguiculata L.) germplasm using morphological and molecular characterisation," Cogent Food and Agriculture, vol. 3, p. 1, 2017.

[53] H. Xiong, A. Shi, B. Mou et al., "Genetic diversity and population structure of cowpea (Vigna unguiculata L. Walp)," PLoS ONE, vol. 11, Article ID e0160941, 2016.

[54] C. Fatokun, G. Girma, M. Abberton et al., "Genetic diversity and population structure of a mini-core subset from the world cowpea (Vigna unguiculata (L.) walp.) germplasm collection," Scientific Reports, vol. 8, p. 16035, 2018.

[55] A. Kilian, G. Sanewski, and L. Ko, "The application of DArTseq technology to pineapple," Acta Horticulturae, vol. 1111, no. 1111, pp. 181-188, 2016.

[56] L. Horn and H. Shimelis, "Production constraints and breeding approaches for cowpea improvement for drought prone agro-ecologies in Sub-Saharan Africa," Sciences Volume, vol. 65, no. 1, pp. 83-91, 2020.

[57] W. Muchero, JD. Ehlers, TJ. Close, and P. A. Roberts, "Mapping QTL for drought stress-induced premature senescence and maturity in cowpea [Vigna unguiculata (L.)W alp.]," Theoretical and Applied Genetics, vol. 118, pp. 849-863, 2009a.

[58] W. Muchero, N. N. Diop, P. R. Bhat et al., "A consensus genetic map of cowpea [Vigna unguiculata (L) walp.] and synteny based on EST-derived SNPs," Proceedings of the National Academy of Sciences, vol. 106, no. 43, pp. 1815918164, 2009b.

[59] L. Pan, N. Wang, Z. Wu et al., "A high density genetic map derived from RAD sequencing and its application in QTL analysis of yield-related traits in Vigna unguiculata," Frontiers in Plant Science, vol. 8, p. 1544, 2017.

[60] W. Ravelombola, A. Shi, and B.-L. Huynh, "Loci discovery, network-guided approach, and genomic prediction for drought tolerance index in a multi-parent advanced generation intercross (MAGIC) cowpea population," Horticulture Research, vol. 8, no. 1, p. 24, 2021.

[61] E. B. Kouam, T. Ngompe-Deffo, M. Anoumaa, and R. S. Pasquet, "Preliminary study on character associations, phenotypic and genotypic divergence for yield and related quantitative traits among cowpea landraces (Vigna unguiculata) from the Western Highland Region of Cameroon," Open Agriculture, vol. 3, no. 1, pp. 84-97, 2018.

[62] W. Ravelombola, A. Shi, Y. Weng et al., "Association analysis of salt tolerance in cowpea (Vigna unguiculata (L.) walp) at germination and seedling stages," Theoretical and Applied Genetics, vol. 131, no. 1, pp. 79-91, 2018.

[63] S. Franzel, L. Hitimana, and E. Akyeampong, "Farmer participation in on-station tree species selection for agroforestry: a case study from Burundi," Experimental Agriculture, vol. 31, no. 1, pp. 27-38, 1995.

[64] L. W. Kitch, O. Boukar, C. Endondo, and L. L. Murdock, "Farmer acceptability criteria in breeding cowpea," Experimental Agriculture, vol. 34, no. 4, pp. 475-486, 1998.

[65] MJ. Ngaka and E. M. Zwane, "The role of learning networks in agricultural extension service delivery: a survey in the nine provinces of South Africa," South African Journal of Agricultural Extension, vol. 45, no. 2, pp. 26-37, 2018.

[66] N. Maruzani, "Problems faced by rural women in Buhera district of Manicaland South province of Zimbabwe," Journal of Emerging Trends in Educational Research and Policy Studies (JETERAPS), vol. 5, no. 3, pp. 370-376, 2014.

[67] J. Mubaiwa, V. Fogliano, C. Chidewe, EJ. Bakker, and A. R. Linnemann, "Utilization of Bambara groundnut (Vigna subterranea (L.) verdc.) for sustainable food and nutrition security in semi-arid regions of Zimbabwe," PLoS ONE, vol. 13, no. 10, Article ID e0204817, 2018.

[68] C. Masegela and I. Oluwatayo, "Value chain mapping and marketing efficiency of smallholder cowpea farmers in Capricorn and Waterberg districts of Limpopo province," The 56 th Annual Conference of Agriculture Economics of South Africa, pp. 25-27, 2018.

[69] I. Maseko, T. Mabhaudhi, S. Tesfay, H. T. Araya, M. Fezzehazion, and C. P. Du Plooy, "Review. African leafy vegetables: a review of status, production and utilization in South Africa," Sustainability, vol. 10, p. 16, 2018.

[70] N. Sharma, A. Sharma, and P. Sharma, "Farmers' preferences to varietal attributes as an indicator for acceptance and adoption of aromatic rice (oryza sativa) varieties," Indian Journal of Agricultural Sciences, vol. 87, pp. 51-55, 2016. 
[71] NL. Ntshangase, B. Muroyiwa, and M. Sibanda, "Farmers' perceptions and factors influencing the adoption of No-till conservation agriculture by small-scale farmers in zashuke, KwaZulu-natal province," Sustainability, vol. 10, p. 555, 2018.

[72] NM. Thompson, C. Bir, DA. Widmar, and J. R. Mintert, "Farmer perceptions of precision agriculture technology benefits," Journal of Agriculture and Applied Economics, vol. 51, pp. 1-22, 2018.

[73] MK. Maredia, R. Shupp, E. Opoku et al., "Farmer perception and valuation of seed quality: evidence from bean and cowpea seed auctions in Tanzania and Ghana," Agricultural Economics, vol. 50, pp. 1-13, 2019. 